\title{
The Implementation of the Common Assessment Framework at the General Hospital of Attica “KAT”
}

\author{
Odysseas Kopsidas \\ University of Piraeus, Piraeus, Greece
}

\begin{abstract}
This paper discusses the implementation of the Common Assessment Framework (CAF) in the Greek civil service. CAF is based on the principles of total quality management (TQM) and is a tool for improving the performance of public bodies. Key element in its implementation is the dimension of organization self-assessment. This article defines the conceptual framework and analyses the management terms related to its application. Methods used include a review of academic and practical literature, as well as the case study of a particular department of the Greek public administration: a public hospital. In addition, the paper presents the prerequisites for CAF implementation and provides a detailed description of the criteria. Finally, implementation progress in the selected public service is assessed and some recommendations for improvement are made. In conclusion, good practices and lessons learned from the implementation of the CAF are discussed.
\end{abstract}

Keywords: CAF, TQM, Greek Public Administration, self-assessment, assessment criteria

\section{Introduction}

This paper focuses on the implementation of the Common Assessment Framework (CAF) in the Greek civil service. The CAF is based on the principles of total quality management (TQM) and is a tool for improving the performance of public organizations. In the context of its implementation, the core element is the self-assessment of organizations and staff, the preparation of an improvement plan based on the evaluation, and its implementation (Anastasopoulou, 2010). This paper defines a conceptual framework and analyses management terms related to its application. Next, the methodological framework, based on the review of academic and practical literature and the in-depth case study of a particular organizational unit of the Greek public administration, a public hospital, is defined (Charalamopoulou, 2010).

Analysis of the implementation is divided into three parts, following a three-step adaptation model. Thus, the first step concerns the mapping of the ex-ante situation before the introduction of CAF to the organization and the presentation of the institutional and legislative framework governing the CAF in Greece (Dimitrova, 2002). In the second part, an in-depth study of the administrative change in an organization unit of the Greek civil service (Papanastasiou, 2015), in the case of the CAF implementation is conducted (Michalopoulos, Polykratis, \& Dimitriou, 2017). Finally, in Part Three, the progress of implementation in the selected public

Odysseas Kopsidas, Ph.D., Lecturer, Research Fellow, Department of Industrial Management and Technology, University of Piraeus, Piraeus, Greece.

Correspondence concerning this paper should be addressed to Odysseas Kopsidas, Department of Industrial Management and Technology, University of Piraeus, Karaloli \& Dimitriou 80, Piraeus 18534, Greece. 
service will be assessed and some suggestions for improvement will be made (Karipidou, 2011). In conclusion, good practices and lessons learned from the implementation of the CAF are discussed (Engel, 2002).

\section{Methodology}

Interview is one of the research tools (as well as the questionnaire and observation), which are applied inter alia in the Social Sciences (Osman et al., 2014). Often, relevant research, particularly at postgraduate level, is limited to applying a written questionnaire and marginalizes or ignores other research tools (Dutch Ministry of Social Affairs and Employment, 2008). The interviewer may include questions that allow penetration and deepening into some of the aspects of the problem under consideration, which are not easy, at least with the same effort to deepen, be included in a questionnaire: personal thoughts, attitudes, causes of behavior, fears, insecurity, etc. (Europol, 2008).

The duration of the survey, distribution and submission of questionnaires, data collection, and processing lasted six months. The by the simple method of rating was followed, as suggested by the CAF Guide. In addition, the proposed multi-phase CAF method has been followed (Giannakopoulou, 2011). The hospital applied CAF to the following departments: the Department of Accident and Emergency (hereinafter referred to as A \& E), the All-day Operation (Afternoon Doctors), and the Financial Department. In order to draw conclusions about the application of this tool to the hospital, the first department was chosen because of its importance in the operation of each hospital.

\section{Case Study: Department of Accident \& Emergency "KAT" General Hospital}

The General Hospital of Attica KAT is a legal entity governed by public law principally in Traumatology and Orthopedics and is under the control and supervision of the Governor of the 1st Attica Health Region. According to data kept at the hospital, it has 549 beds and employs a total of 1,285 workers, while in 2017, 24,564 patients were hospitalized (Ministry of Administrative Reconstruction, 2013). With the decision (614/13-09-2017) of the hospital manager, the CAF was implemented from December 2017. Based on the above decision, the CAF implementation team was set up and notified to the Ministry of Administrative Reconstruction on 13-09-2017. The above group consists of nine members from different departments.

The A \& E has cross-sectoral staffing and operates 24 hours a day with eight shifts, while in 2017; the total number of those surveyed amounted to 95,954. It is the link between pre-hospital and in-patient care. It also acts as a filter that protects the hospital from unnecessary hospitalizations. The A \& E is one of the main gateways to the hospital. Thus, in 2017, out of a total of 220,803 visits to the hospital, that department accounted for $43 \%$, or 95,954. As regards the methodology of implementation, 120 employees of the department participated, of whom 85 were clinical and laboratory directors, on-call doctors, heads of administrative departments, social workers, psychologists, five physicians, 21 nurses, two injuries, and four exclusive radiology technicians. Also, the sample was categorized by department of employment, position of responsibility and level of education based on its particular demographic characteristics, such as age and gender, 77 employees of all specialties responded.

The plenary of the working group kept the simple way of rating. In addition, the management team also participated in the rating group, which contributed to the improvement actions. The rating of the criteria was attended by seven of the nine members of the team, due to obligations to the service. For the measurement of patient satisfaction, 280 questionnaires were distributed, of which 139 by the patients during their release or 
during their time at the department's waiting room, from 15 December to 15 January 2019, from the total of respondents the highest percentage was given by men (72), aged 18 to 45 (74), university graduates or technological educational institute graduates (49) residents of the Prefecture of Attica (126), of Greek nationality (114), the cause of visit was accident (75), the place of the event was Attica (124), average attendance private car (118), while 18 of the 139 subjects went through ambulance. The SPSS statistical tool was used to analyze the survey results. Based on citizens' rating (4.08), citizens-patients perception of on-call duty, treatment of cases, quality, validity, and trust, a high level of satisfaction, adequacy and effectiveness is shown. Improvement measures have been proposed, such as the right of the public to systematically measure or improve the parking space with special provision for people with disabilities.

\section{Conclusion}

In order to assess effectively the results of the implementation of the Common Assessment Framework in KAT, and for a more comprehensive understanding of its implications in the wider public sector, the method of interviews was followed, as already mentioned. Interviews were conducted with the head of the KAT evaluation team, as well as with senior staff from various services, based on the questionnaire prepared by the authors and included in the appendix. In the question of determining the procedure followed regarding the choice of the implementation of the CAF, the respondents claimed that it was a decision of the service itself. In addition, with regard to the implementation of the CAF by 2009, some respondents agreed that the circulars and the effort to disseminate information on the CAF made by the competent Directorate of the Ministry of Internal Affairs contributed to the direction of the implementation of the CAF. Concerning the existence of previous applications of CAF in services, the two cases examined (KAT, General Secretariat for Equality of the Ministry of the Interior) were the first application. Fragmented CAF applications appear to be the rule in ministries and government agencies, and the number of applications mentioned does not indicate the quality and actual added value of individual applications.

Respondents confirm the finding that CAF applications typically cover a Directorate or a Section and not all entities. The Ministry of Employment and Administrative Reform has implemented it in Directorates. As mentioned in the case study, the application to KAT covered three sections. The applications in the Ministry of Defense during the period 2008-2009, were confined to the drafting service and the hospitals (Navy Hospital, Hospital of Aviation, 401 Military Hospital and "NIMITS" Military Hospital) and were focused on economic-administrative directorate and a nursing section (Ministry of National Defense, 2009). Different practices were identified regarding the use of the questionnaires and sample selection. A random sample of all disciplines and specialties was used by the Manager for the selection of KAT employees. Patients were also randomly selected, but the interval for completing the questionnaires was determined based on hospital constraints. In other cases, the questionnaire was given to all recipients and what was available at the time set was collected and then processed statistically. As far as the groups are concerned, the questionnaires were combined in workshops based on the statistical analysis. Before the evaluation was carried out, the existing situation was recorded, leading to obvious assessments (Ministry of Administrative Reconstruction, 2007).

Some respondents also reported that the criteria had been adjusted, in other cases no further adaptation or further specification of the criteria was made. Where the situation was recorded, adaptation/specialization were also reported according to the nature of the subject of each entity. Overall, most interviewees have positively assessed the contribution of CAF as an administrative tool that demonstrates strengths and points of 
improvement in a systematic way. Additionally, positive points are the measurement staff satisfaction, which is conducted for the first-time through CAF, as well as the documentation of the actions, the communication stimulus for the staff to embrace the effort to achieve excellence in the organization. Also, a significant problem is the observed lack of commitment of the top management in the implementation of the CAF, resulting in dispatching applications without continuity and without linking to a certain quality policy.

Concerning the linkage of CAF with targeting and monitoring of KAT indicators, it was reported that the CAF resulted in the creation of plans for improvement and therefore of objectives and action plans. An important parameter in the implementation of the CAF has been to indicate whether results measurements were first introduced and whether they lead to feedback. The linking of the CAF with the National Reform Program's projections and its inclusion in the Quality Action Plan was seen as an auxiliary, but not sufficient condition for the deployment of the tool. CAF should also be included in other sectoral strategies and policies.

For the dissemination of the CAF, the interviewees proposed the implementation of a certifiable standard with a certain duration (e.g., two years) by the Interior Ministry, as civil service organizations would in that case be forced to apply it to their own advantage. Otherwise, it was assumed that even if funding for the implementation would be provided, once it would be discontinued, the implementation would cease. Other respondents reported as incentives the provision of specific legislative and funding to the agency for implementing the actions. Furthermore, the Partnership Agreement could contribute to the dissemination of the CAF although an earlier attempt to do so failed. Finally, the respondents mentioned as the most important factors for the implementation of the process, the commitment of the actors, the motivation and encouragement of staff and the continuing will of the political leadership.

\section{References}

Anastasopoulou, A. (2010). Common Assessement Framework, Total Quality Management Tool in the Public Administration. Improving a Public Organization through the CAF Self-Assessment (dissertation, University of Macedonia).

Charalamopoulou, N. (2010). The common assessment framework as a total quality management tool. Data and perspective for administrative self-evaluation in Greece: The case of education. National School of Public Administration and Local Self-Government. Publish of National School of Public Administration.

Dimitrova, A. (2002). Enlargement, institution-building and the EU's administrative capacity requirement. West European Politics, 25(4), 171-190.

Dutch Ministry of Social Affairs and Employment. (2008). The balance model. Publish of National School of Public Administration.

Engel, C. (2002). Common assessment framework: The state of affairs. Eipascope, 1, 1-5.

Europol. (2008). Application of CAF at Europol. Retrieved from https://slideplayer.com/slide/10465591/

Giannakopoulou, S. (2011). The implementation of total quality management tools in the public and private sector: The case of common assessment framework. Athens: Ministry of Administrative Reform and Electronic Governance.

Karipidou, C. (2011). The experience from the application of the common assessment framework in the Greek Public Administration: Problems, difficulties, benefits, improvement recommendations (dissertation, University of Macedonia).

Michalopoulos, N., Polykratis, D., \& Dimitriou, I. (2017). Guidebook on the implementation of the common assessment framework. Athens: General Directorate of Reform Policy and Electronic Governance, Directorate of Organisational Reforms.

Michalopoulos, N., Ntais, P., \& Psarakis, A. (2007). CAF implementation guide. Athens: Ministry of Interior, Public Administration and Decentralisation.

Ministry of Administrative Reconstruction. (2013). Improving public services through self-assessment (in Greek). EIPA. Publish of National School of Public Administration.

Ministry of Administrative Reconstruction. (2007). Improving a civil service through self-assessment. Publish of National School of Public Administration. 
Ministry of National Defense. (2009). Assessment report and improvement measures report on the application of the common assessment framework in the 1st recruiting command. Athens: Ministry of National Defense.

Osman, I., Latef, A., Zahir, A., Baydaa, I., Ayoubi, A., Lee, H., ... Vishanth Weerakkody, V. (2014). COBRA Framework to evaluate e-government services: A citizen-centric perspective. Government Information Quarterly, 31(2), 30-48.

Papanastasiou, E. (2015). Assessment framework of grouped operations and indicators of management of administrative social services: The case of the university hospital of alexandroupolis (Postgraduate dissertation, Democritus University of Thrace). 


\section{Appendix-Questionnaire}

1. What was the main influence that determined your choice of service to implement the Common Assessment Framework (CAF)?

1. Was it a decision of the service itself?

2. Has it come from pressure outside the service?

3. Was it a product of compliance with rules?

2. Has the CAF been applied to your service in the past?

1. If so, did you rely on the previous approach?

2. You can refer to the reasons why previous efforts have been abandoned.

3. Does the implementation of the CAF cover your entire organization or is it located in a directorate or section?

4. Was the CAF process outsourced or conducted entirely in-house?

5. Did the organization receive assistance in implementing the CAF?

1. Has the Ministry of Administrative Reconstruction assisted?

2. From other agencies?

6. Have the provisions of the CAF Implementation Guide been followed?

1. Operation of the Assessment Team (composition of members)

2. Ways of Documenting Evaluation

7. Have the questionnaire and rating report of the above guide been used?

1. How did you select the sample that completed the questionnaire? (staff / service recipients).

8. How long has the process of self-evaluation been conducted through the CAF?

9. Has the criteria been adjusted or further refined to the needs of the service?

10. What is the overall assessment of the CAF implementation in your service?

1.Positive

2.Negative

3.Restrictions

11. Is the Common Assessment Framework being updated in your organization?

12. How does the CAF relate to the targeting (monitoring of indicators) of your organization and the objectives of each Directorate and Section?

13. What challenges / problems have you encountered in implementing the CAF?
1. Adequacy of guidelines
2. Existence of will for effective implementation
3. Problems in the model of the CAF itself
4. Staff cooperation
5. Ownership of the effort.
6. Support/time

14. Do you consider that the link between the CAF and the National Reform Program is sufficient for the dissemination of the tool?

15. How could the CAF be more widely disseminated and implemented?

1. Legislative provision

2. Incorporation of incentives to implement the CAF. 
16. How do you judge the dissemination of the CAF in the Greek public administration in relation to other EU Member States where it applies?

17. How do you judge the country's compliance with the conditionality of Thematic Objective 11 in particular with regard to the “Action Plan on Target-setting and Quality 2015-2016”?

18. What do you think are the most important factors in implementing the CAF implementation process? (e.g., leadership, commitment, etc.)

19. What is the most important part of the CAF implementation process? (e.g., implementation of improvement actions)

20. Have improvement actions been implemented?

21. What were the reasons for not implementing the improvement actions?

22. Has there been a discrepancy in the rating resulting from the completion of the questionnaire(s) in relation to the self-assessment group rating? If so, where do you attribute this?

23. Do you consider that the CAF can be a tool for rational change in the civil service? 